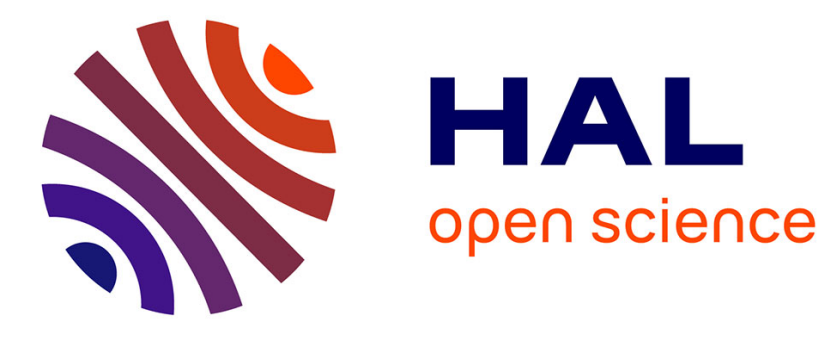

\title{
Phase sensitivity to axial strain of microstrustured optical silica fibers
}

Yohann Léguillon, Pascal Besnard, Laurent Provino, Achille Monteville, Méchin David, Denis Tregoat, Martine Doisy, François-Xavier Launay

\section{- To cite this version:}

Yohann Léguillon, Pascal Besnard, Laurent Provino, Achille Monteville, Méchin David, et al.. Phase sensitivity to axial strain of microstrustured optical silica fibers. 21st International Conference on Optical Fiber Sensors (OFS 2011), May 2011, Ottawa, Canada. pp.77533S, 10.1117/12.884793 . hal-00597340

\section{HAL Id: hal-00597340 \\ https://hal.science/hal-00597340}

Submitted on 31 May 2011

HAL is a multi-disciplinary open access archive for the deposit and dissemination of scientific research documents, whether they are published or not. The documents may come from teaching and research institutions in France or abroad, or from public or private research centers.
L'archive ouverte pluridisciplinaire HAL, est destinée au dépôt et à la diffusion de documents scientifiques de niveau recherche, publiés ou non, émanant des établissements d'enseignement et de recherche français ou étrangers, des laboratoires publics ou privés. 


\title{
Phase sensitivity to axial strain of microstrustured optical silica fibers
}

\author{
Y. Léguillon ${ }^{a, b, c}$, P. Besnard ${ }^{b, c}$, L. Provino ${ }^{d}$, A. Monteville $^{d}$, D. Méchin ${ }^{d}$, D. Trégoat ${ }^{d}$, \\ M. Doisy ${ }^{a}$, F.-X. Launay ${ }^{a}$ \\ ${ }^{a}$ Thales Underwater Systems, 525 route des Dolines, 06903 Sophia Antipolis, France; \\ ${ }^{b}$ Université Européenne de Bretagne, Enssat, Rennes, France; \\ ${ }^{c}$ CNRS, UMR 6082 FOTON, 6 rue de Kerampont, BP 80518, 22305 Lannion, France; \\ ${ }^{d}$ PERFOS, 11 rue Louis de Broglie, 22300 Lannion, France
}

\begin{abstract}
We compare, thanks to a Sagnac interferometer, the phase sensitivity to strain of different microstructured optical silica fibers (MSF) that we design and fabricate. Our results show that when a same elongation is applied to different MSF, the induced phase change is equal or lower than the one obtained for a standard fiber, showing no advantage on this parameter for sensing applications.
\end{abstract}

Keywords: Microstructured silica fiber, optical fiber sensors, phase sensitivity, acoustic sensors

\section{INTRODUCTION}

Fiber optic hydrophone based on interferometric sensors have advantages over conventional piezoelectric ones. ${ }^{1}$ However, this interferometric optical technology is complex and has a relatively big size. Distributed feedback fiber laser could be a solution to these inconvenients. ${ }^{2}$ These fiber laser sensors have already been used in multiplexed hydrophone arrays ${ }^{3}$ even if improvements on the size of the mechanical system have to be made. Preliminary work ${ }^{4}$ seems to indicate that the phase sensitivity of an hollow-core photonic bandgap silica fiber to an axial strain due to acoustic pressure is improved because of the presence of air holes. The goal of this paper is to experimentally check whether MSF, on which we can potentially inscribe a Bragg grating, are much more sensitive to an axial strain or not than standard silica fibers.

\section{EXPERIMENTAL SET-UP}

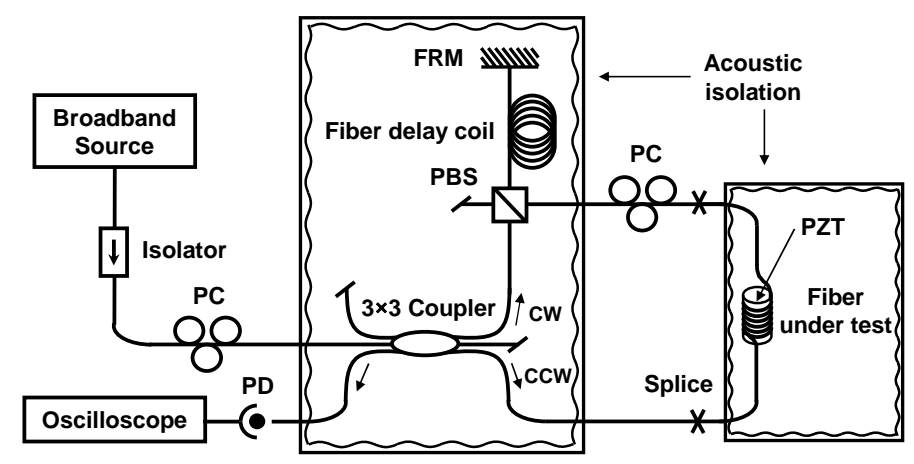

Figure 1. Sagnac interferometer. PC: Polarization controller; PD: Photodiode; PBS: Polarization beam splitter; FRM: Faraday rotator mirror; PZT: Piezoelectric transducer; CW: clockwise; CCW: counterclockwise.

The experimental set-up consists in a Sagnac interferometer shown on figure 1, commonly used as a fiber optic gyroscope or acoustic sensor. ${ }^{5}$ Light from a broadband source is split into clockwise $(\mathrm{CW})$ and counterclockwise (CCW) beams by a $3 \times 3$ coupler. The $\mathrm{CW}$ and $\mathrm{CCW}$ have asymmetric path as the $\mathrm{CW}$ beam crosses first the delay coil and then the fiber under test (FUT) while the CCW propagates through these different elements in 
the reverse order. Each FUT is wrapped around the same cylindrical piezoelectric transducer (PZT), cleaved and directly spliced to the standard fiber in the interferometer. The PZT is driven by an alternative voltage to periodicaly pull and release the FUT, thus allowing the intrinsic sensitivity of the fiber to an axial strain to be measured. The fiber-length modulation causes a change in the propagation phase. It follows, at a given time, a phase difference between the two counter-propagating beams, because they do not meet the PZT at the same time. The phase modulation is converted into a power modulation when the beams recombine at the $3 \times 3$ coupler. If an alternative voltage, modulated at the frequency $\Omega$ and applied to the PZT induces a phase modulation $\phi_{h} \cos (\Omega)$, the output power of the interferometer is then given by ${ }^{5}$

$$
P(t)=P_{0}\left[1+v \cdot \cos \left\{2 \cdot \phi_{h} \cdot \eta \cdot \sin \left(\Omega t+\frac{\Omega \tau}{2}\right)+\frac{\pi}{3}\right\}\right],
$$

where $P_{0}$ is a power scaling factor, $v$ the interference visibility, $\phi_{h}$ the phase modulation amplitude, $\tau$ the fiber delay time, $\eta=\sin (\Omega \tau / 2)$ the sensitivity of the Sagnac interferometer.

The $3 \times 3$ coupler is used in order to passively bias the interferometer close to the quadrature at the phase bias $\pi / 3$. To avoid acoustic perturbations, the test part and the interferometer are acoustically isolated. A polarization beam splitter (PBS) and a Faraday rotator mirror (FRM) reduce polarization induced signal fading, which simplified measurements by stabilizing the interferometer. Polarization controllers were used to maximize the amplitude and visibility of the detected signal. Note that as the Sagnac is a common-path interferometer, it is insensitive to the source phase noise.

By interchanging the FUT, it is possible to compare the results obtained with a standard silica fiber and with different MSF.

\section{THE MICROSTRUCTURED OPTICAL SILICA FIBERS}

Microstructured fibers are nowadays well-known speciality fibers. Their design could bring several advantages such as a smaller effective area in order to reach higher intensities in the waveguide commonly to lower nonlinear threshold, or on the contrary large effective area while maintaining single mode operation, or the realization of a desired optical bandwidth, or lower losses to bends. Three MSF have been tested. Their scanning electron microscopy images are given on figure 2 and their design parameters in table 1 . They have not been manufactured especially for this study. They have been chosen among MSF singlemode at $1550 \mathrm{~nm}$ available at PERFOS. Nevertheless, their different design could give us an idea of their sensitivity to an axial strain.

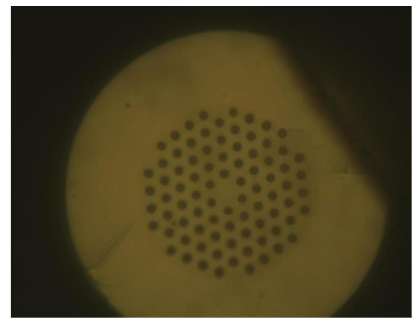

(a) HF 148

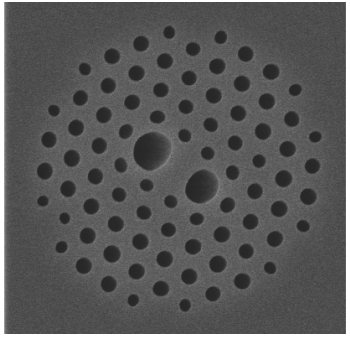

(b) HF 174

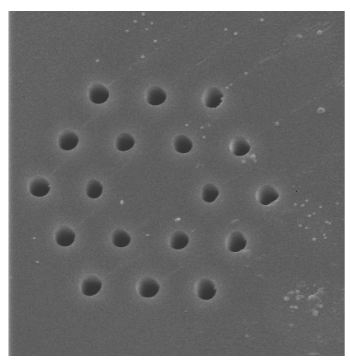

(c) HF 202

Figure 2. Scanning electron microscopy images of microstructured silica fibers.

Table 1. Design parameters of the microstructured silica fibers. $d$ is the air-holes diameter. $\Lambda$ is the pitch between air-holes. $\mathrm{N}_{r}$ is the number of holes rings.

\begin{tabular}{|c|c|c|c|}
\hline Fiber & $\mathbf{d}(\mu \mathrm{m})$ & $\Lambda(\mu \mathrm{m})$ & $\mathbf{N}_{r}$ \\
\hline HF 148 & $\approx 1.8$ & $\approx 6.8$ & 5 \\
\hline HF 174 & - & $\approx 2$ & 5 \\
\hline HF 202 & $\approx 2$ & $\approx 6$ & 2 \\
\hline
\end{tabular}




\section{EXPERIMENTAL RESULTS}

The fiber delay coil was about $5 \mathrm{~km}$ long. Because light passes twice through it, the effective loop length was twice that of an unfolded coil, which is $10 \mathrm{~km}$. It corresponds to a loop proper frequency of $\approx 10.3 \mathrm{kHz}$, which is the frequency to set the sensitivity $\eta$ at 1 .

The interferometer output power is converted into a voltage by the photodiode and is read onto an oscilloscope. A typical response observed for a fiber SMF 28 is given on figure 3.

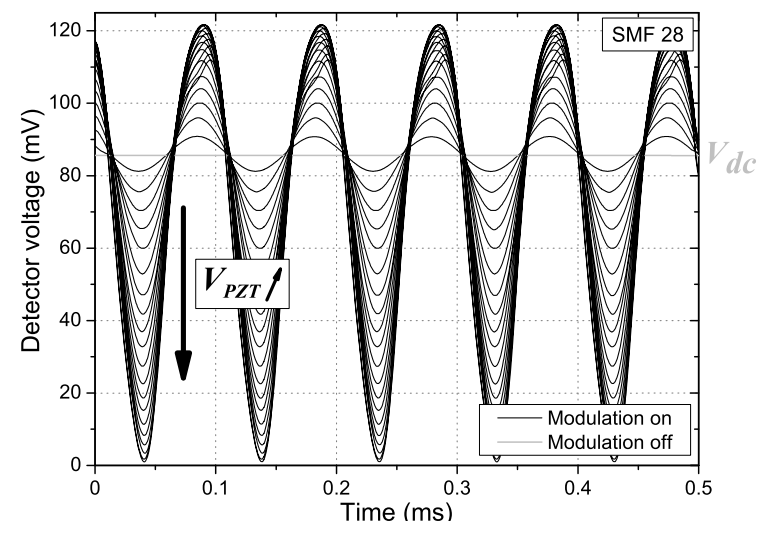

Figure 3. Example of results with standard fiber SMF 28.

When the PZT is not modulated, we obtain a continuous voltage called $V_{d c}$. When it is modulated by a voltage $V_{P Z T} \cos \left(2 \pi f_{p} t\right) / 2$, we obtain "pseudo"-sines (see equation (1)), whose amplitude increases when $V_{P Z T}$ increases. The power received by the photodiode depends on the FUT because of splice losses. So, to compare the different fibers, we measure, for a given amplitude $V_{P Z T}$, the peak-to-peak voltage $V_{p-p}$ of interferences normalised by the voltage $V_{d c}$. Measurements for each fiber are presented on figure 4 where $V_{p-p} / V_{d c}$ is plotted versus the applied voltage on PZT. We can observe that MSF are not more sensitive to strain than the standard fiber SMF 28. For small phase shift amplitude, which corresponds to the linear part of the curve 4(a), we have

$$
\frac{V_{p-p}}{V_{d c}} \approx 4 \sqrt{3} \cdot \frac{v}{v+2} \cdot \eta \cdot \phi_{h},
$$

where $v$ is the visibility, $\eta$ the sensitivity and $\phi_{h}$ the phase modulation amplitude. On figure 4(b), we linearly

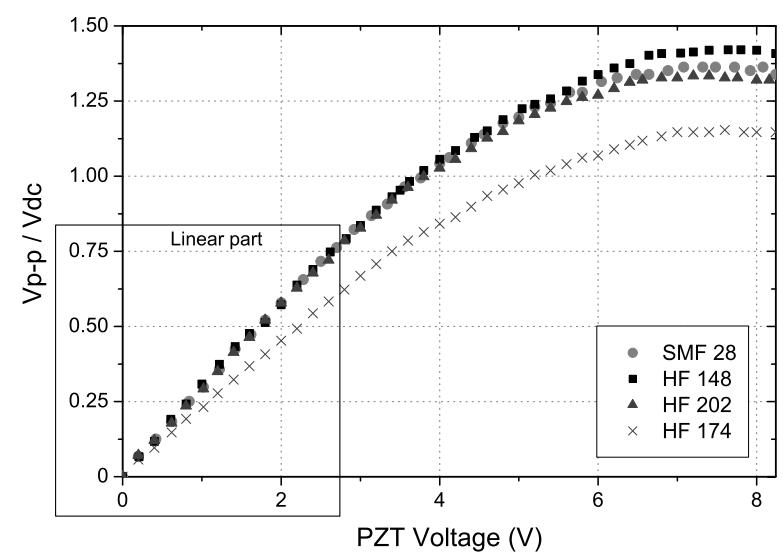

(a) Set of measures

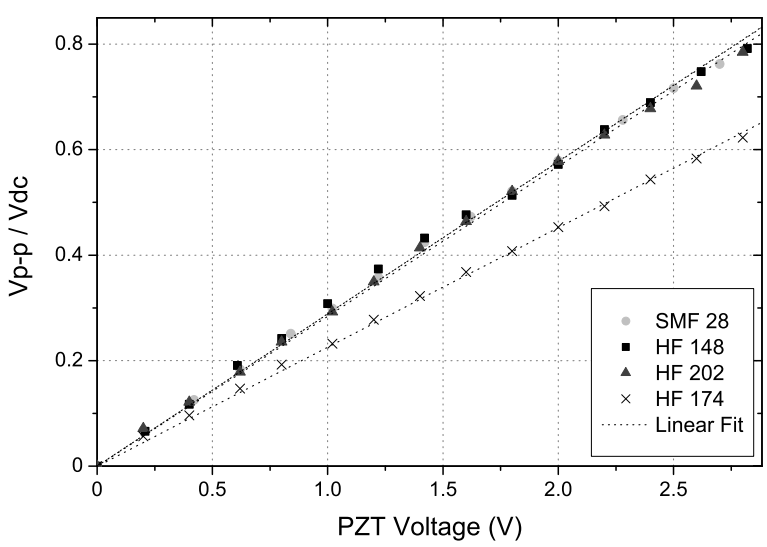

(b) Zoom on linear part

Figure 4. Sensitivity to strain; comparison of the 3 fibers. 
fitted curves in order to obtain the slope for each fiber. Since we fixed both visibility $v$ and sensitivity $\eta$ to be equal to 1 , we can determine the sensitivity $\phi_{h} / V_{P Z T}$ (in rad/V) to an axial strain for each fiber from equation (2). These sensivities are 0.125 rad/V for both SMF 28 and HF 148, $0.123 \mathrm{rad} / \mathrm{V}$ for HF 202 and $0.098 \mathrm{for} \mathrm{HF}$ 174. For a standard fiber, the relationship between the relative phase shift and the applied axial strain $\epsilon_{z}$ is given by 6

$$
\frac{\partial \phi}{\phi}=\left[1-P_{e}\right] \cdot \varepsilon_{z}
$$

where $P_{e}=\left(n^{2} / 2\right)\left[p_{12}-\nu\left(p_{11}-p_{12}\right)\right]$ is the effective strain-optic constant, $n$ is the effective index, $p_{i j}$ are the Pockel's coefficients of the stress-optic tensor and $\nu$ is Poisson's ratio. With the PZT used here, and considering $P_{e}$ for standard silica fibers ${ }^{6}$ equal to 0.22 , we should measure a sensitivity $\phi_{h} / V_{P Z T}$ of $\approx 0.117 \mathrm{rad} / \mathrm{V}$. Our results are in agreements with theory. However, the sensitivity of the HF 174 is lower than others. As a matter of fact, the high birefringence of the fiber implies that not all the optical power is on the same birefringent axis even if a polarization controller is used. As in our set-up, the normalization is set over the total intensity, while the measurement concerns the axial strain along with an unique birefringent axis, the phase sensitivity is under estimated. We think that if we could align properly the polarization axis, the results would have been similar to the other fibers. It shows the limitation of our bench when highly birefringent fibers are under test. Note that the use of all polarization maintaining fibers and components will not improve anything as far as the broadband source is not linear polarized. However, we made up the choice of showing the obtained results for such birefringent MSF in order to give an order of magnitude of phase sensivity. For MSF, if we consider more in details the different parameters of $P_{e}$, this study confirms a posteriori that $P_{e}$ cannot signicantly be changed even with the presence of air-holes.

\section{CONCLUSION}

In this communication, we have experimentally shown that microstructured silica optical fibers have the same sensitivity than standard fibers when an axial strain is applied. These results can be summed up by the fact that the induced phase change for a given strain is, to the first order, determined by the silica material elasto-optic properties. However, future prospects with MSF are the use of radial stress or the use of multimaterial fiber taking benefits of the aire holes. Another idea is to expose MSF directly to acoustic pressure. The induced axial strain to MSF (thus induced phase change) will be as large as the air-filling ratio.

\section{ACKNOWLEDGMENTS}

The authors want to acknowledge S. Blin for all his advices and discussions. The authors thank the French territorial and governmental organizations that partially funded this work through the "Sea Innovation \& Business cluster (Pôle Mer) ATOS project.

\section{REFERENCES}

[1] Kirkendall, C. and Dandridge, A., "Overview of high performance fibre-optic sensing," Journal of Physics D: Applied Physics 37, R197 (2004).

[2] Cranch, G., Foster, S., and Kirkendall, C., "Fiber laser strain sensors: enabling a new generation of miniaturized high performance sensors," Proc. SPIE 20th Int. Conf. Optical Fibre Sensors 7503, 750352-1-750352-4 (2009).

[3] Hill, D., Nash, P., Jackson, D., Webb, D., O’Neill, S., Bennion, I., and Zhang, L., "Fiber laser hydrophone array," Proceedings of SPIE 3860, 55 (1999).

[4] Pang, M. and Jin, W., "Phase sensitivity of hollow-core photonic bandgap fiber to acoustic pressure," Proc. SPIE 20th Int. Conf. Optical Fibre Sensors 7503, 75035Z.1-75035Z.4 (2009).

[5] Blin, S., Bishop, M., Parameswaran, K., Digonnet, M. J. F., and Kino, G. S., "Pickup suppression in sagnacbased fiber-optic acoustic sensor array," IEEE Journal of Lightwave Technology 24, 2889-2897 (July 2006 ).

[6] Kersey, A., Davis, M., Patrick, H., LeBlanc, M.and Koo, K., Askins, C., Putnam, M., and Friebele, E., "Fiber grating sensors," IEEE Journal of Lightwave Technology 15(8), 1442-1463 (1997). 